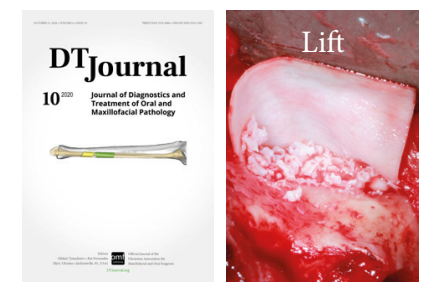

\title{
Sinus Lift: Analysis of Schneiderian Membrane Perforations
}

Sir:

Complications appeared during or after the sinus membrane elevation are under meticulous investigation of different specialists. ${ }^{1}$ Among peroperative ones are: sinus membrane perforation, hemorrhage/bleeding, buccal bone fracture, nonachievement of primary stability, and infraorbital nerve injury. ${ }^{1}$ Postoperative complications are usually divided into acute and chronic: ${ }^{2}$ bleeding, graft leak, wound opening, infections, endosinus extrusion of the implant, and modification of the mucosa. ${ }^{1}$

According to Barone et $\mathrm{al}^{3}$ a Schneiderian membrane (synonym: mucoperiosteal lining of the maxillary sinus) perforation is the most common complication (noted in the 25 percent of performed sinus lifts). Some studies reported even 56 percent of perforation accidents. ${ }^{1}$

Two different classifications of sinus membrane perforations are applied according to a 1) lateral or 2) transcrestal sinus floor elevation. In cases of lateral (synonyms: direct, open $)^{4}$ lift the perforations are divided into IV Classes ${ }^{5}$ proposed by Fugazzotto and Vlassis in 2003 which became a simplified version of the 1999 's V Classes Classification ${ }^{6}$ developed by the same authors.

The 2003's Classification by Fugazzotto and Vlassis includes Class I, II, III (which can be IIIA [along the lateral or cranial wall of the created window, when a

Please cite this article as: Nagorniak IV. Sinus lift: analysis of Schneiderian membrane perforations. J Diagn Treat Oral Maxillofac Pathol 2020;4(10):191-3.

The word 'Lift' at the upper right icon means that article focused on sinus floor elevation. cavity to be augmented extends a minimum of 4-5 $\mathrm{mm}$ beyond the perforation with additional space for performance of a further osteotomy] and IIIB [the same as upon IIIA but without the additional space for osteotomy]), and IV.

In cases of transcrestal lift the perforations are classified by Tavelli et $\mathrm{al}^{7}$ into three types:

- Type I - small perforation caused by an implant drill.

Type $I_{1}$ - large perforation caused by a drill.

- Type II - perforation caused by uncontrolled forces applied during Schneiderian membrane elevation or resulting from membrane collapse during grafting, with the consequent graft migration into the sinus.

- Type III - can occur during dental implant placement and be hidden by the implant body.

\section{HOW TO AVOID PERFORATION?}

Becker et $\mathrm{al}^{8}$ and Tourbah with Maarek ${ }^{1}$ described the factors that can increase the risk of sinus membrane perforation: 1) previous entrance into the sinus (ie, scarring), 2) septa, 3) thin membrane, 4) soft tissue adhesion, 5) cyst/sinus pathology, 6) operator error, and 7) overfilling with the graft material

Kendrick insisted ${ }^{9}$ - to reducing risk of perforation can be achieved by the ultra-careful evaluation of

Paper received 15 September 2020

Accepted 11 October 2020

Available online 31 October 2020

https:// doi.org/10.23999/j.dtomp.2020.10.2.

(C) 2020 OMF Publishing, LLC. This is an open access article under the CC BY license (https://creativecommons.org/licenses/by-nc/4.0/). 
preoperative CT for assessment of:

1. The thickness of the sinus bone wall.

2. Location of septa.

3. Membrane thickness: the incidence of perforation is higher when the thickness is less than $1.5 \mathrm{~mm} .{ }^{1}$

\section{MANAGEMENT}

Hernández-Alfaro et $\mathrm{al}^{10}$ in 2008, presented six solutions for the perforations: suturing (in 11 percent of cases), resorbable collagen membrane (42.30 percent), lamellar bone + resorbable collagen membrane (26.92 percent), lamellar bone (3.84 percent), lamellar bone + buccal fat pad $(9.61$ percent), and bone block graft (5.76 percent).

Barbu et $\mathrm{al}^{11}$ in 2019 published their two management techniques for tearing: suturing (in 51 percent of cases) and sealing using a low-resorption collagen membrane (in 49 percent).

Beck-Broichsitter et al ${ }^{12}$ in 2020 reported their six ways of perforations' management: no treatment, suture, fibrin glue, collagen membrane, suture + fibrin glue, and suture + collagen membrane. In 56 percent of cases the perforation was covered by membrane and in 20 percent a suture with membrane was applied.

Thus, the results of all three groups of surgeons demonstrate a strong position $(42.30,49$, and 56 percent) of resorbable collagen membrane application among other perforation restorative techniques.

In my practice the resorbable collagen membrane is a preventive measure used in all cases of the direct lift, regardless of whether there is a perforation or not (Fig 1). But we should remember the thesis highlighted by Younes and Boukaram: when the perforation reparation is impossible, the lift is aborted and reentry is planned after 3 months. ${ }^{13}$
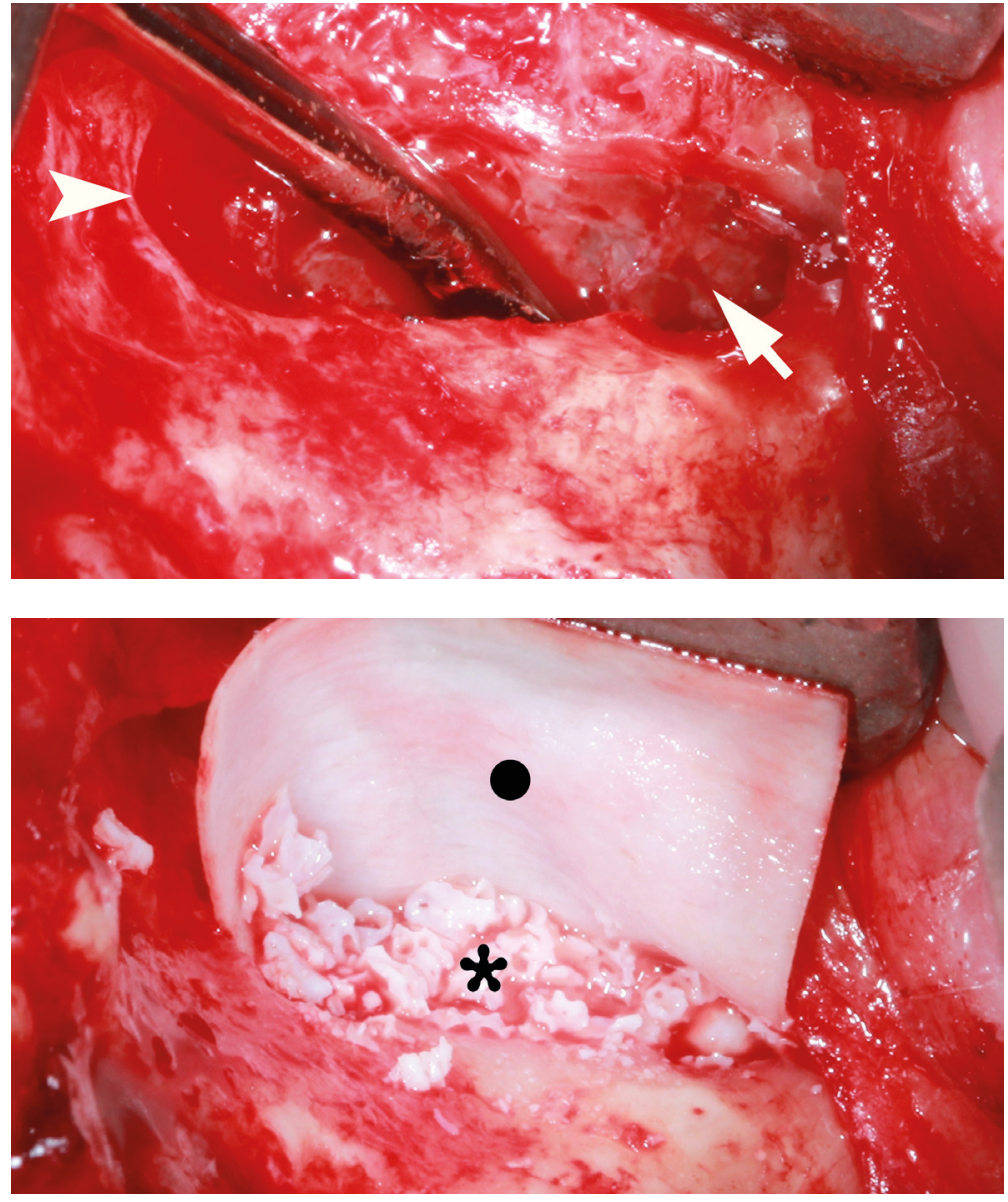

FIGURE 1. Uncomplicated lateral (arrowhead) sinus floor elevation (using a complete osteotomy design) ${ }^{4}$ in a 37-year-old male. No evidence of Schneiderian membrane (arrow) perforations $(\mathbf{A})$ is noted. Bone grafting using spongious bovine bone material (1-2 mm granules) (asterisk) simultaneously with a $25 \times 25-\mathrm{mm}$ resorbable collagen membrane (dot) was used as a preventive measure $(\mathbf{B})$. 


\section{PIEZOSURGERY}

Considering the data that piezosurgery offers a 75 percent reduction in the expected Schneiderian membrane perforation rate, piezosurgery becomes a must have equipment for all clinics focused on sinus grafting. ${ }^{13}$ As for me, a prolonged transoperative time $^{14}$ and a cost of piezosurgical equipment are only two minor disadvantages of that technology.

Summarizing the data, it's important to emphasize the importance of resorbable collagen membrane usage in cases of small $(<5 \mathrm{~mm})$, large $(5-10 \mathrm{~mm})$, and even complete sinus membrane tears (large dilacerations). ${ }^{1}$ Collagen membrane usage even in non-perforated cases is highly recommended taking into account my own experience.

Ivan V. Nagorniak, Oral Surgeon, PhD

Private Practice

6-G Andruschenka Street, Office 6

Kyiv 01135, Ukraine

E-mail:ivan.nagorniak@gmail.com

\section{REFERENCES}

1. Tourbah B, Maarek H. Complications of maxillary sinus bone augmentation: prevention and management. In: Younes R, Nader N, Khoury G, editors. Sinus grafting techniques. Cham: Springer; 2015:195-233. https://doi.org/10.1007/978-3-31911448-4_8

2. Kim J, Jang H. A review of complications of maxillary sinus augmentation and available treatment methods. J Korean Assoc Oral Maxillofac Surg 2019;45(4):2204. https://doi.org/10.5125/jkaoms.2019.45.4.220

3. Barone A, Santini S, Sbordone L, Crespi R, Covani U. A clinical study of the outcomes and complications associated with maxillary sinus augmentation. Int $J$ Oral Maxillofac Implants 2006;21(1):81-5.

4. Nagorniak IV. Lateral sinus lift. J Diagn Treat Oral Maxillofac Pathol 2020;4(9):178. https://doi. org/10.23999/j.dtomp.2020.9.4

5. Fugazzotto PA, Vlassis J. A simplified classification and repair system for sinus membrane perforations. J Periodontol 2003;74(10):1534-41. https://doi. org/10.1902/jop.2003.74.10.1534
6. Vlassis JM, Fugazzotto PA. A classification system for sinus membrane perforations during augmentation procedures with options for repair. J Periodontol 1999;70(6):692-9. https://doi. org/10.1902/jop.1999.70.6.692

7. Tavelli L, Borgonovo AE, Saleh MH, Ravidà A, Chan HL, Wang HL. Classification of sinus membrane perforations occurring during transcrestal sinus floor elevation and related treatment. Int $J$ Periodontics Restorative Dent 2020;40(1):111-8. https://doi. org/10.11607/prd.3602

8. Becker ST, Terheyden H, Steinriede A, Behrens E, Springer I, Wiltfang J. Prospective observation of 41 perforations of the Schneiderian membrane during sinus floor elevation. Clin Oral Implants Res 2008;19(12):1285-9. https://doi.org/10.1111/j.16000501.2008.01612.x

9. Kendrick DE. Management of complications of sinus lift procedures. In: Tolstunov L, editor. Horizontal alveolar ridge augmentation in implant dentistry: a surgical manual. 1st ed. Hoboken, New Jersey: Wiley; 2016:194-8. https://doi.org/10.1002/9781119082835. ch19

10. Hernández-Alfaro F, Torradeflot MM, Marti C. Prevalence and management of Schneiderian membrane perforations during sinus-lift procedures. Clin Oral Implants Res 2008;19(1):91-8. https://doi. org/10.1111/j.1600-0501.2007.01372.x

11. Barbu HM, Iancu SA, Jarjour Mirea I, Mignogna MD, Samet N, Calvo-Guirado JL. Management of Schneiderian membrane perforations during sinus augmentation procedures: a preliminary comparison of two different approaches. J Clin Med 2019;8(9):1491. https://doi.org/10.3390/jcm8091491

12. Beck-Broichsitter BE, Gerle M, Wiltfang J, Becker ST. Perforation of the Schneiderian membrane during sinus floor elevation: a risk factor for long-term success of dental implants? Oral Maxillofac Surg 2020;24(2):151-6. https://doi.org/10.1007/s10006020-00829-8

13. Younes R, Boukaram M. Lateral sinus grafting approach: overview and recent developments. In: Younes R, Nader N, Khoury G, editors. Sinus grafting techniques. Cham: Springer; 2015:65-103. https:// doi.org/10.1007/978-3-319-11448-4_5

14. Comparison between piezosurgery and rotative instruments in maxillary sinus lifting. A systematic review. Clin Oral Impl Res 2017;28(S14):476. https:// doi.org/10.1111/clr.473_13042 